\title{
Supplier Assessment and Selection Using Fuzzy Analytic Hierarchy Process in a Steel Manufacturing Company
}

\author{
Farzad Tahriri $^{{ }^{*}}$, Mohammad Dabbagh $^{2}$ and Nader Ale Ebrahim ${ }^{3}$ \\ ${ }^{1}$ Centre for Product Design and Manufacturing, Department of Engineering Design and \\ Manufacture, Faculty of Engineering, University of Malaya, 50603, Kuala Lumpur, Malaysia. \\ ${ }^{2}$ Department of Software Engineering, Faculty of Computer Science and Information \\ Technology, University of Malaya, 50603, Kuala Lumpur, Malaysia. \\ ${ }^{3}$ Research Support Unit, Centre of Research Services, Institute of Research Management \\ and Monitoring (IPPP), University of Malaya, Malaysia.
}

Authors' contributions

This work was carried out in collaboration between all authors. All authors read and approved the final manuscript.

Original Research Article

Received $23^{\text {rd }}$ December 2013

Accepted $25^{\text {th }}$ March 2014

Published 5 ${ }^{\text {th }}$ April 2014

\section{ABSTRACT}

Every organization needs suppliers and no organization can exist without suppliers. Therefore, the organizations approach to suppliers and the selection of the appropriate supplier, its acquisition processes and policies, and its relationships with suppliers, is of vital importance, both to organizations and suppliers alike. No organization can be successful without the support of its supplier base, operationally and strategically, short or long-term. To select the best supplier, it is essential to make an analytical decision based upon tangible and intangible criteria. Chose and management of a supplier has to be congruent with organizational strategy. Therefore, the vision and strategy of the manufacturer are the key drivers for how the supply function will be managed and how supply decisions are made and exectuted. The proposed model in this study was applied in a steel manufacturing company in Malaysia with the goal of reducing time in choosing the correct supplier for the company. This study aims to provide a systematic model stimulating correct supplier selection using the Fuzzy Analytic Hierarchy Process (FAHP) method along with a series of sensitivity analyses which were conducted using the Expert Choice (EC) program to evaluate the impact of changes in the priority of criteria for the 
suppliers' performance and order quantities.

Aims: The main goal of this research is to develop a systematic model towards the best supplier selection. To facilitate the aim of the research, we utilized the Fuzzy Analytic Hierarchy Process, which was a combination of AHP and Fuzzy Theory in order to deal with the uncertainties and vagueness of decision makers' judgement.

Study Design: Mention the design of the study here.

Place and Duration of Study: The data samples were taken in a steel manufacturing company in Malaysia.

Methodology: A Fuzzy Analytic Hierarchy approach is used using a quantitative and qualitative criteria for selecting and evaluating a suitable supplier selection and a six step was conducted to ensure successful implementation.

Results: The results indicate that the model is able to assist decision makers to examine the strengths and weaknesses of supplier selection by comparing them with appropriate criteria, sub-criteria and sub sub-criteria.

Conclusion: We developed a Fuzzy AHP multi-criteria decision making model for supplier evaluation and selection in the ABC steel company in Malaysia. The advantage of the proposed model over other models like the AHP is that, by adoption of fuzzy numbers, it effectively improves the flexibility of the conventional AHP in dealing with the uncertainty and ambiguity associated with different decision makers' judgments.

Keywords: Fuzzy Analytic Hierarchy Process (FAHP); supplier selection; Total Value of Purchasing (TVP).

\section{INTRODUCTION}

In most industries the cost of raw materials and components is the major cost of the product, such that in some cases it can account for up to $70 \%$ [1]. In the current economic climate, decision making in purchase management could play a key role in cost reduction. In today's highly competitive environment, an effective supplier selection process is very important to the success of any manufacturing organization [2].

The special scheme discussed in this paper, known as the $A B C$, is intended for the steel industry in Malaysia. Business activities and services of $A B C$ Steel company provide both mechanical and structural Steel design, engineering, procurement, construction, installation and commissioning services for Steel mills such as: Limekilns, Hydration \& PCC plants, power plants, cement plant and storage tanks, chemical and industrial plants, piping works, paints shop, machinery and plant installation, customized design items \& maintenance, commercial building steel structure and roof steel structures and steel bridges. While the majority of $A B C$ 's projects are in Malaysia, $A B C$ also supplies and manufactures for projects in other countries, such as Indonesia, Singapore, Papua New Guinea.

Selecting the appropriate vendor is always a difficult task for buyers. Suppliers have varied strengths and weaknesses, which require careful evaluation by buyers before ranking, can be given to them. The supplier selection process will be simple if only one criterion was used in the decision making process. However, in many cases, buyers have to take account of a range of criteria in making its decisions. If several criteria are used then it is necessary to determine how far each criterion influences the decision making process, If all are to be equally weighted or whether the effect will vary accordingly to the type of criteria [3]. The $A B C$ model development for steel manufacturing company for selection of suppliers must be 
made not only to ensure benefits to the buyer's customers, but also to order raw materials on account of the following reasons:

(1) Huge variety of finished products, and thus a great need for raw materials.

(2) The large number of projects in process.

(3) The huge fluctuations in price for raw materials such as: mild steel sheets, stainless steel and UB steel.

(4) The large number of suppliers providing varieties in qualitative and quantitative criteria.

The vendor selection problem is a group Multiple Criteria Decision-Making (MCDM) out of that amount criteria have been considered for supplier selection in the previous and current decision models so far [4]. Multiple Criteria Decision-Making (MCDM), a problem is influenced by two conflicting factors in supplier selection, for which a purchasing manager must analyze the trade off between the various criteria. MCDM techniques support the decision-makers (DMs) in the assessment of a set of alternatives [5]. Depending upon the purchasing conditions, criteria have different importance and there is a need to weigh them [6].

For Multiple Criteria Decision-Making (MCDM) problem of $A B C$ steel manufacturing company a unique and appropriate method is required to facilitate vendor selection and therefore provide the company with a proper and cost-effective system of ordering raw materials.

The analytic hierarchy process (AHP) has found widespread application in decision-making issues, involving several criteria in the systems of many levels [2,7]. This method is the ability to structure complex, multi-person, multi-attribute, and the multi-period issue hierarchy [8]. The AHP approach can be useful in involving several decision-makers with various contradictory aims to arrive at a consensus decision $[9,10]$. Considering the problems existing in the company start from the wrong vendor selection, due to human errors in the assessment of the raw materials, or pay too much attention to one factor only, such as price, cost and other similar and unexpected problems, the AHP model is recommended to handle the supplier choice more precisely in order to mitigate, or better yet, eliminate the errors on this line $[11,12]$.

There various solution approaches to supplier selection problem in the literature. Some of which are Analytic Hierarchy Process, Fuzzy Analytic Hierarchy Process, Data Envelopment Analysis, Mixed Integer Programming, TOPSIS, Fuzzy TOPSIS, QFD, Fuzzy QFD, Analytic Network Process and Expert Systems [11]. Researches carried out in the area of supplier selection have been implementing multi-criteria decision making methods, such as Fuzzy analytic hierarchy process (FAHP), analytic network process (ANP), data envelopment analysis (DEA), and mathematical programming $[13,14,15,16,17,18,19]$.

The AHP approach, since its invention, it is one of the most extensively used multiple criteria decision-making tools in the hands of decision makers and researchers [20]. Many remarkable works have been published based on AHP. They include application of AHP in different fields such as planning, selecting the best alternative, resource allocations, resolving conflict, optimization, etc., as well as numerical extensions of AHP [21]. Among the application of the AHP method in the field by choosing the best alternative, some publications are specified in supplier selection, e.g. [1,2,9,10,22,23]. 
Despite the popularity of AHP and its simplicity in concept, we have found out that it involves a major disadvantage which makes it inefficient and inflexible to be applied for priority evaluation and assessment of appropriate supplier selection. It has been generally criticized that AHP is not sufficient to take into account the uncertainty and ambiguity associated with human decision [24]. Since our desired supplier selection model is subjective and involves various decision makers during the priority setting process, it has a characteristic of ambiguity and uncertainty. So, in such a situation, it is not a good option to use AHP. Therefore, in this work, we have tried to address this problem through our model. Laarhoven and Pedrycz [25] proposed the Fuzzy Analytic Hierarchy Process, that was an application of a combination of AHP and Fuzzy Theory in order to deal with the uncertainties and vagueness of decision makers' judgment. Zadeh [26] first proposed Fuzzy Theory, which is able to accept, in our case, uncertain judgment from decision makers. After accepting input, fuzzy set theory then determines the extent to which these contributions belong to the corresponding fuzzy sets. This process would then be followed by defuzzification process, which produces a measurable result usually in the form of a numerical value. By integrating fuzzy set theory, AHP is able to handle the ambiguity of the data involved in the decision making effectively.

\section{SUPPLIER SELECTION}

One the main aspects of the procurement function is vendor selection criteria. The analysis of criteria for the selection and measurement of the performance of suppliers has been the focus of attention of many scientists and purchasing professionals since 1960's. In the mid 1960 's, researchers are developing performance criteria on which potential suppliers can be assessed [27]. Dickson [28] firstly carried out an extensive study to determine, identify and analyse what criteria are used in the selection of a firm as a supplier. Dickson study [28] was based on a survey sent to 273 purchasing agents and managers selected from the membership list of the National Association of Purchasing Managers. The list includes purchasing agents and managers from the United States and Canada, which was a total of 170 (62.3 of Dickson's study) concerning the importance of 23 criteria for supplier (vendor) selection. Dickson asked the respondents evaluate the importance of each criteria on a five point scale of: extreme, considerable, average, slight and of no importance. Based on respondents' reply "quality" is the main criterion followed by "delivery" and "performance history". Weber, Current and Benton [29] presented a classification of all articles published since 1966 according to the treated criteria. Based on 74 papers, the outputs observe that Price, Delivery, Quality and Production capacity and location were the criteria most often treated in the literature.

According to [29], the review of the articles on Supplier selection (SS) between 1966 and 1991 was studied and in a related study, [30], 49 articles collected between 1991 and 2003, was a comprehensive classification of supplier selections released. The study of Zhang et al. [30] has been done based on Weber, Current and Benton study [29] and the 23 criteria of Dickson study [28]. The study concluded that the net price, quality, and delivery were the most significant supplier selection criteria. As concluded from three different studies, price is the number one selection factor, replacing Dickson [28] number one ranked quality requirements [31]. Along with the well-noted research studies of $[28,29,30]$, other researchers have also recently began discussing the importance of extra supplier selection criteria, not mentioned in the above studies. Another study [32], which sampled eighty (80) manufacturing firms, discovered that quality, price, technical service, delivery, reliability, and lead time were among the most important selection factors. The definitions of Dickson [28] 23 criteria have been expanded and some new criteria were developed with the growth of 
new business needs. The review performed in [33] concluded that the most valuable supplier selection criteria were cost, quality, service, relationship, and organization [31].

Davidrajuh [34] reviewed of some studies which highlight the important criteria and their invariance. While a number of supplier selection criteria studies have been conducted over the years, Dickson [28], Weber, Current and Benton [29] and Zhang, Lei, Cao and Ng [30] still recognize as the most common, and cited as the most comprehensive study done on selection criteria.

$\mathrm{Ku}$, Chang, and $\mathrm{HO}$ [35], based on a literature review, identify criteria for global supplier selection grouped as: cost or price, quality, service, supplier's profile, risk, buyer-supplier partnership, cultural and communication barriers and trade restrictions. Kahraman, Cebeci, and Ulukan [36] proposes four groups of supplier performance criteria: supplier's profile, product performance, service performance and cost performance. Awasthi, Chauhan, and Goyal [37] proposed criteria for evaluation of environmental performance of suppliers.

\section{MODEL DEVELOPMENT}

The purpose of this work is to develop a supplier selection using Fuzzy AHP approach. In compliance with the collection of quantitative and qualitative data for Fuzzy AHP supplier selection model that may be used by the steel manufacturing company, a six step approach was conducted to ensure successful implementation as follows:

\subsection{Define Criteria for Supplier Selection}

The first step in any vendor rating procedure is to establish the criteria to be used to evaluate the supplier. To meet the criteria for supplier selection and their importance, the necessary data is collected based on the consideration of the earlier study [31]. Therefore, the 13 important criteria have been selected. After defining the criteria for the selection of the supplier, the first structured interview was designed based on the inputs received; an additional criterion is added such that the respondents were asked to indicate the importance of each criteria by using numbers from 1 to 9 . In order to determine the relevant criteria, the respondents were asked to rate each factor using the four-point scale of "Not important (1 to 3$)$ ", "somewhat important (4 to 5)", "Important (6 to 7$)$ " and "Very important (8 to 9)" [9]. This structured interview consisted of: the general characteristics of the company, the model or the type of method used for supplier selection, and providing the 13 items that indicates the best selection criteria for supplier selection.

Before the beginning of the study, according to the Fuzzy AHP method, the structured interview is completed by a related specialist (the procurement manager) assessment of the criteria. Interviews were carried out with three members of the ABC Engineering Steel Company namely, the two project managers and a purchasing manager represented in order by (R1), (R2) and (R3) respectively. This test was performed, on account of its importance in supplier selection and up-grading the decision making accuracy. The resultant structured interviews were sent to the selected respondents. The results of the case study is summarized in Fig. 1. The respondents were asked to include the additional criteria that seemed important, in the structured interviews, and identify their level of importance. Having received the inputs of the respondents, the criteria were identified and averaged. In addition, the presence of too many criteria makes the pairwise comparisons in evaluating suppliers a difficult and time consuming process. To resolve these problems, the cut-off value to reduce 
the number of criteria to a few is desirable [9]. In order to choose the most important criteria, it was intended to accept the criteria with average above 7 . Finally, the effective extremely important criteria such as quality, delivery, direct cost, trust, financial and management and organization were selected at level (2) in supplier selection model (The goals factor in Level (1) for supplier selection model is to select the best overall supplier).

\subsection{Define Sub Criteria and Sub sub-criteria for Supplier Selection}

In this stage, the definition of the sub criteria and sub sub-criteria have been done for supplier selection based on the eight important criteria chosen as the result of the previous step with the review of the literature. Design and modification of identifying sub and subcriteria, also respondents, selection of the second structured interview, have been doing similar to the first step.

By the second structured interview, it becomes possible to find sub and sub sub-criteria. One of the problems involved in sending the questionnaires to the proper authorities and getting their response, as well as to minimize the efforts, second structured interviews were applied to cover two goals.

- To find sub-criteria and sub sub-criteria.

- To weight and compare pairwise for all criteria, sub-criteria and sub sub-criteria.

After receiving the inputs of the respondents, the criteria were identified and averaged. Nine sub criteria and thirty sub sub-criteria were selected for levels (3) and (4) in supplier selection model as shown in (Fig. 2).

\subsection{Structure the Hierarchical Model}

This phase consists of building the Fuzzy AHP hierarchy model and calculation of the weight of each level of supplier selection model. The developed Fuzzy AHP model, based on the identified criteria, sub criteria and sub sub-criteria, contains five levels: the goal, the criteria, sub-criteria, sub-sub criteria and alternatives. (Fig. 2) shows an illustrative 5-level hierarchy for the supplier selection problem. The objective of our problem in the selection of the supplier for the steel manufacturing company in Malaysia is identified in the first level. The second level (criteria) contains: cost, delivery, quality, management and organization, trust and financial. The third and fourth level of the hierarchy consists 9 sub criteria and 30 sub sub-criteria, which were identified in the previous section. The lowest level of the hierarchy contains of the alternatives, namely the different supplier to be evaluated in order to select the best supplier. As shown in (Fig. 2), four suppliers were used to represent arbitrarily the ones that the firm wishes to evaluate. The Fuzzy AHP model shown in (Fig. 1) is generally applicable to any supplier selection problem of "ABC" steel manufacturing company that a team wishes to evaluate, as it covers the critical factors and relevant criteria and sub criteria and sub sub-criteria for supplier selection of a steel manufacturing company. 


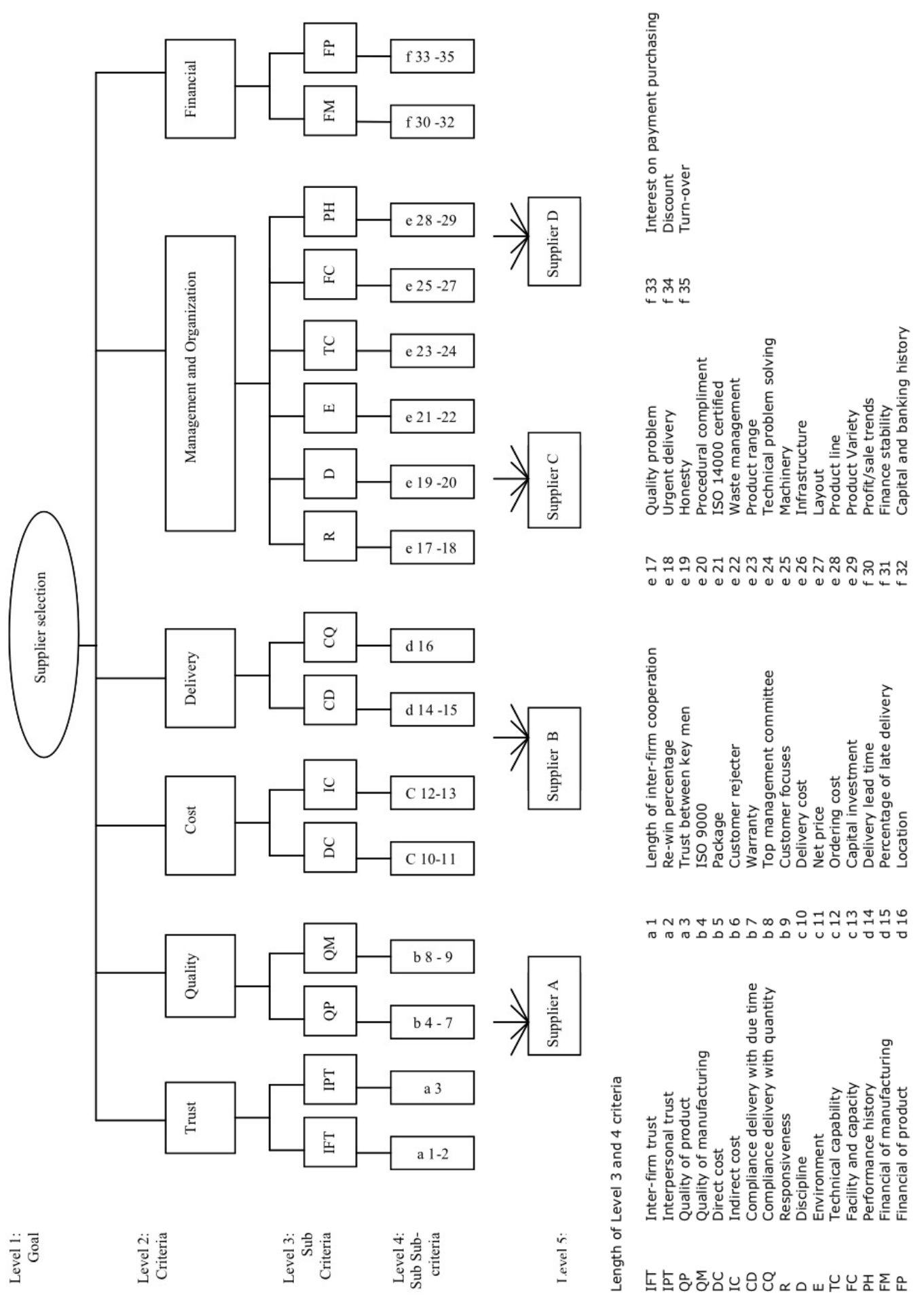

Fig. 1. An illustrative decision hierarchy for supplier selected [31] 


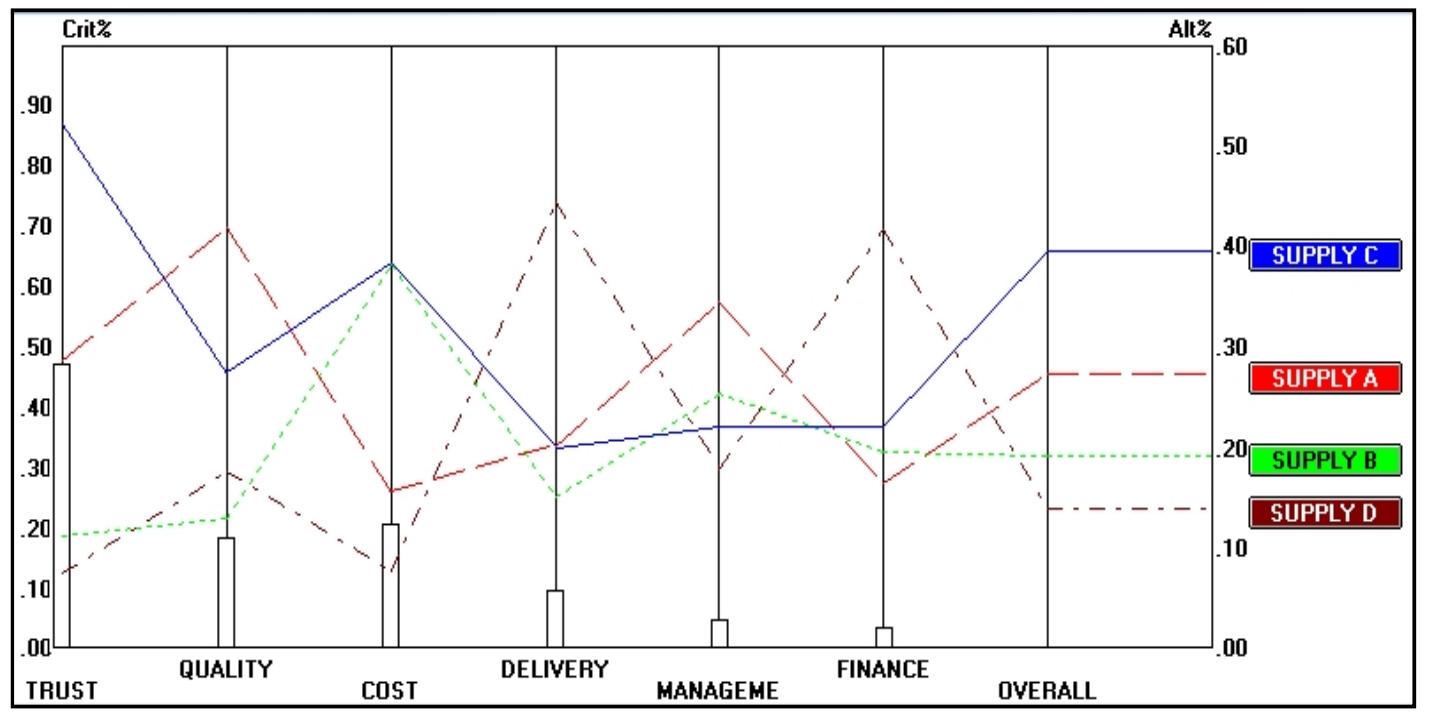

Fig. 2. Perform sensitivity analysis of supplier selection

\subsubsection{Collecting the priority weight for each level of fuzzy AHP hierarchy model}

To complete the model at this point, a priority weight of each criterion in each level was determined. A second structure, an interview consisting of all factors in each level of the Fuzzy AHP model is used to collect the pairwise comparison judgments by all evaluation team members. This determination is performed by using pairwise comparisons. The function of the pairwise comparisons is to find the relative importance of the criteria and sub criteria which is rated by the nine-point scale proposed by Saaty [38], as shown in Table 1, which indicates the level of relative importance from equal, moderate, strong, very strong, to extreme level by $1,3,5,7$, and 9 , respectively. The intermediate values between two adjacent arguments were represented by $2,4,6$, and 8 .

Table 1. Measurement scales [38]

\begin{tabular}{ll}
\hline Verbal judgment or preference & Numerical rating \\
\hline Extremely preferred & 9 \\
Very strongly preferred & 7 \\
Strongly preferred & 5 \\
Moderately preferred & 3 \\
Equally preferred & 1 \\
Intermediate values between two adjacent & $2,4,6$ and 8 \\
judgments (when compromise is needed) & \\
\hline
\end{tabular}

A sample of the pairwise comparison matrix in level 2 of the supplier selection model based on data collected from the decision maker number (1) is shown in Table 2. 
Table 2. An example of pairwise comparison matrix for decision maker number (1)

\begin{tabular}{lllllll}
\hline Criteria for Supplier selection & T & Q & C & D & MO & F \\
\hline Trust (T) & 1 & 4 & 3 & 6 & 6 & 7 \\
Quality (Q) & $1 / 4$ & 1 & 1 & 3 & 5 & 6 \\
Cost (C) & $1 / 3$ & 1 & 1 & 3 & 6 & 6 \\
Delivery (D) & $1 / 6$ & $1 / 3$ & $1 / 3$ & 1 & 4 & 5 \\
Management and Organization (MO) & $1 / 6$ & $1 / 5$ & $1 / 6$ & $1 / 4$ & 1 & 2 \\
Financial (F) & $1 / 7$ & $1 / 6$ & $1 / 6$ & $1 / 5$ & $1 / 2$ & 1 \\
\hline
\end{tabular}

\subsubsection{Set up triangular fuzzy numbers}

In this step, Fuzzy AHP is applied to convert the opinions of respondents from previous definite values to fuzzy numbers in order to enhance the accuracy and flexibility of respondents' comparison judgments. In order to reach a consensus among the respondents, the triangular fuzzy number (TFN) is calculated. TFN is capable of aggregating the subjective opinions of all respondents through fuzzy set theory. TFN denoted as (L, M, $\mathrm{H}$ ) which represents the highest possible value, most ideal value, and lowest possible value, respectively. The triangular fuzzy number $T_{-} x y$ is defined using the equation (1), and (2):

$$
\begin{aligned}
& T_{x y}=\left(L_{x y}, M_{x y}, H_{x y}\right), \quad L_{x y}, M_{x y}, H_{x y} \in\left(\frac{1}{9}, 9\right) \\
& M_{x y}=\sqrt[n]{J_{x y a} \cdot J_{x y b} \cdot J_{x y c} \cdots J_{x y n}}
\end{aligned}
$$

Where $x$ and $y$ represents a pair of criteria, sub-criteria, and sub sub-criteriabeing judged by decision makers; $I_{x y n}$ indicates an opinion of decision maker " $n$ " toward the relative importance for criteria $x$ and $y\left(C_{x}, C_{y}\right)$; and $M_{x y}$ is generated by calculating the geometric mean of decision makers' scores for a particular comparison. The geometric mean is capable of accurately aggregating and representing the consensus of decision makers [38].

\subsubsection{Constructing the fuzzy pairwise comparison matrix}

After calculating the TFN value for level 2 of Fuzzy AHP hierarchy model, a fuzzy pairwise comparison matrix is constructed in the form of $n \times n$ a matrix, where $n$ is the number of criteria as illustrated in Table 3 . This step is also applied on level 3 and level 4 of the supplier selection model.

\subsubsection{Defuzzification process}

This study used the alpha cut approach, proposed by Lious and Wang [39], as shown in equation (3), to perform the defuzzification process. The defuzzification is applied in order to convert the calculated TFN values into quantifiable values.

$$
\mu_{\alpha, \beta}\left(\tilde{F}_{x y}\right)=\left[\beta \times f_{\alpha}\left(L_{x y}\right)+(1-\beta) \times f_{\alpha}\left(H_{x y}\right)\right], \quad 0 \leq \alpha, \beta \leq 1
$$

Where $\tilde{F}_{x y}$ is the fuzzy pairwise comparison matrix; $f_{\alpha}\left(L_{x y}\right)=\left(M_{x y}-L_{x y}\right) \times \alpha+L_{x y}$ represents the left-end boundary value of alpha cut for $\tilde{F}_{x y}$; and $f_{\alpha}\left(H_{x y}\right)=H_{x y}-$ $\left(H_{x y}-M_{x y}\right) \times \alpha$ indicates the right-end boundary value of alpha cut for $\tilde{F}_{x y}$. 
In this context, $\alpha$ and $\beta$ carry the meaning of preferences and risk tolerance of decision makers, respectively. These two values range between 0 and 1 , in such a way that a lesser value indicates greater uncertainty in decision making. Since preferences and risk tolerance are not the focus of this paper, value of 0.5 is used for $\alpha$ and $\beta$ to represent a balance environment. This indicates that decision makers are neither extremely optimistic nor pessimistic about their judgments.

Table 3. Fuzzy pairwise comparison matrix

\begin{tabular}{|c|c|c|c|c|c|c|}
\hline $\begin{array}{l}\text { Criteria for } \\
\text { Supplier selection } \\
T_{x y}=\left(L_{x y}, M_{x y}, H_{x y}\right)\end{array}$ & $\mathbf{T}$ & $\mathbf{Q}$ & C & D & MO & $\mathbf{F}$ \\
\hline Trust $(\mathrm{T})$ & 1 & $(3,3.915,5)$ & $(3,3.915,5)$ & $(6,6,6)$ & $(6,6.952,8)$ & $(7,7.319,8)$ \\
\hline Quality (Q) & & 1 & $(1,1,1)$ & $(2,2.884,4)$ & $(4,4.932,6)$ & $(5,5.944,7)$ \\
\hline Cost (C) & & & 1 & $(3,3.915,5)$ & $(5,5.944,7)$ & $(6,6.952,8)$ \\
\hline Delivery (D) & & & & 1 & $(3,3.915,5)$ & $(4,4.932,6)$ \\
\hline Management and & & & & & 1 & $(2,2.289,3)$ \\
\hline \multicolumn{7}{|l|}{ Organization (MO) } \\
\hline Financial $(F)$ & & & & & & 1 \\
\hline
\end{tabular}

\subsubsection{Calculating the eigenvalues of fuzzy pairwise comparison matrix}

In this step, we try to determine eigenvalues of the fuzzy pairwise comparison matrix. The purpose of calculating eigenvalues is to determine the aggregated weightage of a particular criteria. In fact, it expresses the priority value of each criteria. To estimate the eigenvalues, we utilized a method known as averaging over normalized columns [38]. First, calculate the sum of the ${ }^{n}$ columns in the fuzzy pairwise comparison matrix. Next, divide each element in the matrix by the sum of the column the element is a member of and calculate the sum of each row. Then, normalize the sum of the rows (divide each row sum with the number of requirements). Table 4 shows the result of the computation of priority matrix which is an estimation of the eigenvalues of the fuzzy pairwise comparison matrix obtained from the defuzzification process.

Table 4. The normalized matrix of paired comparisons and calculation of priority weights

\begin{tabular}{lllllllll}
\hline $\begin{array}{l}\text { Criteria for } \\
\text { supplier selection }\end{array}$ & T & Q & C & D & MO & F & Sum & Result \\
\hline Trust (T) & 0.513 & 0.594 & 0.607 & 0.418 & 0.300 & 0.258 & 2.689 & 0.448 \\
Quality (Q) & 0.130 & 0.150 & 0.153 & 0.205 & 0.213 & 0.208 & 1.059 & 0.176 \\
Cost (C) & 0.130 & 0.150 & 0.153 & 0.276 & 0.256 & 0.243 & 1.208 & 0.201 \\
Delivery (D) & 0.085 & 0.051 & 0.039 & 0.070 & 0.170 & 0.173 & 0.588 & 0.098 \\
Management and & 0.073 & 0.030 & 0.026 & 0.018 & 0.043 & 0.083 & 0.273 & 0.046 \\
$\begin{array}{l}\text { Organization (MO) } \\
\text { Financial (F) }\end{array}$ & 0.069 & 0.025 & 0.022 & 0.014 & 0.018 & 0.035 & 0.183 & 0.031 \\
\hline
\end{tabular}

The Consistency Ratio (C.R.) for the comparison above is calculated to determine the acceptance of the priority weighting. The consistency test is one of the essential features of the FAHP method which aims to eliminate the possible inconsistency revealed in the criteria weights, through the computation of the consistent level of each matrix. The software 
system called expert choice is used to determine the normalized priority weights. The Consistency Ratio (CR) was used to determine and justify the inconsistency in the pairwise comparison made by the respondents. Based on [38] empirical suggestion that a C.R. = 0.10 is acceptable, it is concluded that the foregoing pairwise comparisons to obtain attribute weights are reasonably consistent. If the CR value is lower than the acceptable value, the weight results are valid and consistent. In contrast, if the CR value is larger than the acceptable value, the matrix results are inconsistent and are exempted for the further analysis.

Table 5 exhibits the local weights for each criterion in each level. The results show that in the second level of criteria, trust with a local weight of $(0.448)$ had been prioritized as the first criteria followed by cost $(0.201)$, quality $(0.176)$, delivery (0.098), management and organization (0.046) and financial (0.031). The prioritized of sub criteria in the third level and sub-sub criteria in the fourth level also depend on the local weights. The global weights are calculated by multiplying the local weights with criteria, sub criteria and sub sub-criteria.

\subsection{Prioritize the Order of Criteria or Sub Criteria}

Having completed mathematical calculations, comparisons of criteria and allocating weights for each criterion in each level is performed. As indicated in the previous section (Priority weights for alternatives versus attribute and prediction priority), according to the results of each criterion weights define important criteria arrangement and classified in each level for selecting the supplier.

After calculating the global weights of each sub sub-criteria of level 4 , the result is rearranged in descending order of priority, as shown in Table 6. The ranking list of critical success factors can be seen that trust and cost factors occupy the top ranking in the list, the top rank being the trust between key men $(0.3575)$, followed by net price $(0.1457)$ and rewin percentage $(0.0700)$. The quality and delivery factors that are in the top ten ranking include percentage late delivery (0.0643), warranty $(0.0618)$, customer rejection $(0.0483)$, customer focuses $(0.0297)$, the delivery cost $(0.0265)$, ordering cost $(0.0229)$ and ISO9000 (0.0223).

\subsection{Measure Supplier Performance}

The main reason for adopting this method is the evaluation of supplier for a particular steel manufacturing company. After weighting the Fuzzy AHP model for determining priority weight for alternatives and testing the model, the third structured interview was designed and modifies. This interview collects the weightings of alternatives to identify the best supplier. In this step, to determine the priority weight for alternatives, the competitive rivals that are actually the suppliers who are supposed to be used for the ABC steel engineering company were compared. After finding the local weights of each alternative, the global weights of each alternative in each level can be calculated. The global weights evaluation of each alternative can be obtained through multiplying the global weights of sub sub-criteria by the local weights of each alternative. The results and priority weight for each alternative are shown in Table 7. 
Table 5. Composite priority weights for sub sub-criteria

\begin{tabular}{|c|c|c|c|c|c|c|}
\hline Criteria & Local Weights & Sub Criteria & Local Weights & Sub sub-criteria & Local Weights & Global Weights \\
\hline \multirow[t]{3}{*}{ Trust } & 0.448 & Inter-firm trust & 0.202 & Length of inter-firm cooperation & 0.227 & 0.0205 \\
\hline & & & & Re-win percentage & 0.733 & 0.0700 \\
\hline & & Interpersonal trust & 0.798 & Trust between key men & 1.000 & 0.3575 \\
\hline \multirow[t]{6}{*}{ Quality } & 0.176 & Quality of & 0.798 & Customer rejecter & 0.344 & 0.0483 \\
\hline & & product & & Warranty & 0.440 & 0.0618 \\
\hline & & & & ISO 9000 & 0.159 & 0.0223 \\
\hline & & & & Package & 0.057 & 0.0080 \\
\hline & & Quality of manufacturing & 0.202 & Top management committee & 0.166 & 0.0059 \\
\hline & & & & Customer focuses & 0.834 & 0.0297 \\
\hline \multirow[t]{4}{*}{ Cost } & 0.201 & Direct cost & 0.857 & Delivery cost & 0.154 & 0.0265 \\
\hline & & & & Net price & 0.846 & 0.1457 \\
\hline & & Indirect cost & 0.143 & Ordering cost & 0.798 & 0.0229 \\
\hline & & & & Capital investment & 0.202 & 0.0058 \\
\hline \multirow[t]{3}{*}{ Delivery } & 0.098 & Compliance with due time & 0.875 & Delivery lead time & 0.250 & 0.0214 \\
\hline & & & & Percentage late delivery & 0.750 & 0.0643 \\
\hline & & Compliance with quantity & 0.125 & Location & 1.000 & 0.0123 \\
\hline \multirow{13}{*}{$\begin{array}{l}\text { Management } \\
\text { and } \\
\text { Organization }\end{array}$} & 0.046 & Responsiveness & 0.334 & Quantity problem & 0.202 & 0.0031 \\
\hline & & & & Urgent delivery & 0.798 & 0.0123 \\
\hline & & Discipline & 0.337 & Honesty & 0.844 & 0.0131 \\
\hline & & & & Procedural compliment & 0.156 & 0.0024 \\
\hline & & Environment & 0.129 & ISO 1400 & 0.773 & 0.0046 \\
\hline & & & & Waste management & 0.227 & 0.0013 \\
\hline & & Technical capability & 0.084 & Product range & 0.719 & 0.0028 \\
\hline & & & & Technical problem solving & 0.281 & 0.0011 \\
\hline & & Facility and capability & 0.067 & Machinery & 0.359 & 0.0011 \\
\hline & & & & Infrastructure & 0.527 & 0.0016 \\
\hline & & & & Layout & 0.114 & 0.0004 \\
\hline & & Performance history & 0.050 & Product line & 0.224 & 0.0005 \\
\hline & & & & Product variety & 0.776 & 0.0018 \\
\hline \multirow[t]{6}{*}{ Financial } & 0.031 & Manufacturing Financial & 0.881 & Profit/sale trends & 0.148 & 0.0040 \\
\hline & & & & Financial stability & 0.618 & 0.0169 \\
\hline & & & & Capital and banking history & 0.234 & 0.0064 \\
\hline & & Product & 0.119 & Interest on payment & 0.123 & 0.0005 \\
\hline & & Financial & & Discount & 0.683 & 0.0025 \\
\hline & & & & Turn-over & 0.193 & 0.0007 \\
\hline Total & & & & & & 1.0000 \\
\hline
\end{tabular}




\subsection{Identify Supplier Priority and Selection}

Based on the global priority, the weights of each alternative can be evaluated and summarized. The summaries of overall attributes are shown in Table 7. It can be noted that among the four given suppliers, supplier " $\mathrm{C}$ " has the highest weight. Therefore, it must be selected as the best supplier to satisfy the goals and objectives of the ABC steel manufacturing company. Table 6 shows the final score of each supplier $s^{\prime}$ results and ranking. As can be seen, scores of supplier "C" $(0.3947)$ is greater than the other three suppliers' scores such as supplier "A" $(0.2748)$, supplier "B" $(0.1705)$, and supplier "D" (0.1367).

Table 6. Ranking of sub sub-critical

\begin{tabular}{|c|c|c|}
\hline Rank & Critical success factors (Sub sub-criteria) & Global weights \\
\hline 1 & Trust between key men & 0.3575 \\
\hline 2 & Net price & 0.1457 \\
\hline 3 & Re-win percentage & 0.0700 \\
\hline 4 & Percentage late delivery & 0.0643 \\
\hline 5 & Warranty & 0.0618 \\
\hline 6 & Customer rejection & 0.0483 \\
\hline 7 & Customer focuses & 0.0297 \\
\hline 8 & Delivery cost & 0.0265 \\
\hline 9 & Ordering cost & 0.0229 \\
\hline 10 & ISO 9000 & 0.0223 \\
\hline 11 & Delivery lead time & 0.0214 \\
\hline 12 & Length of inter-firm cooperation & 0.0205 \\
\hline 13 & Financial stability & 0.0169 \\
\hline 14 & Honesty & 0.0131 \\
\hline 15 & Urgent delivery & 0.0123 \\
\hline 16 & Location & 0.0123 \\
\hline 17 & Package & 0.0080 \\
\hline 18 & Capital and banking history & 0.0064 \\
\hline 19 & Top management committee & 0.0059 \\
\hline 20 & Capital investment & 0.0058 \\
\hline 21 & ISO 14000 certified & 0.0046 \\
\hline 22 & Profit/sale trends & 0.0040 \\
\hline 23 & Quantity problem & 0.0031 \\
\hline 24 & Product range & 0.0028 \\
\hline 25 & Discount & 0.0025 \\
\hline 26 & Procedural compliment & 0.0024 \\
\hline 27 & Product Variety & 0.0018 \\
\hline 28 & Infrastructure & 0.0016 \\
\hline 29 & Waste management & 0.0013 \\
\hline 30 & Technical problem solving & 0.0011 \\
\hline 31 & Machinery & 0.0011 \\
\hline 32 & Turn over & 0.0007 \\
\hline 33 & Interest on payment & 0.0005 \\
\hline 34 & Product line & 0.0005 \\
\hline 35 & Layout & 0.0004 \\
\hline
\end{tabular}


Table 7. Summarizes of priority weights of each alternative

\begin{tabular}{|c|c|c|c|c|c|c|c|c|c|}
\hline \multirow{2}{*}{$\begin{array}{l}\text { Critical success factors } \\
\text { for supplier selection }\end{array}$} & \multirow{2}{*}{$\begin{array}{l}\text { Global } \\
\text { weights }\end{array}$} & \multicolumn{2}{|c|}{ Supplier (A) } & \multicolumn{2}{|c|}{ Supplier (B) } & \multicolumn{2}{|c|}{ Supplier (C) } & \multicolumn{2}{|c|}{ Supplier (D) } \\
\hline & & $\begin{array}{l}\text { Local } \\
\text { weights }\end{array}$ & $\begin{array}{l}\text { Global } \\
\text { weights }\end{array}$ & $\begin{array}{l}\text { Local } \\
\text { weights }\end{array}$ & $\begin{array}{l}\text { Global } \\
\text { weights }\end{array}$ & $\begin{array}{l}\text { Local } \\
\text { weights }\end{array}$ & $\begin{array}{l}\text { Global } \\
\text { weights }\end{array}$ & $\begin{array}{l}\text { Local } \\
\text { weights }\end{array}$ & $\begin{array}{l}\text { Global } \\
\text { weights }\end{array}$ \\
\hline $\begin{array}{l}\text { Trust Inter firm trust Length } \\
\text { of inter firm cooperation }\end{array}$ & 0.0205 & $0.52=$ & 0.0106 & $0.13=$ & 0.0026 & $0.27=$ & 0.0055 & $0.07=$ & 0.0014 \\
\hline Re-winpercentage & 0.0700 & $0.23=$ & 0.0161 & $0.06=$ & 0.0042 & $0.55=$ & 0.0385 & $0.14=$ & 0.0098 \\
\hline $\begin{array}{l}\text { Inter personal trustTrust } \\
\text { between key men }\end{array}$ & 0.3575 & $0.28=$ & 0.1001 & $0.12=$ & 0.0429 & $0.53=$ & 0.1894 & $0.06=$ & 0.0214 \\
\hline $\begin{array}{l}\text { Quality Product quality } \\
\text { Customer rejecter }\end{array}$ & 0.0483 & $0.57=$ & 0.0275 & $0.06=$ & 0.0028 & $0.22=$ & 0.0106 & $0.13=$ & 0.0062 \\
\hline Warranty & 0.0618 & $0.59=$ & 0.0364 & $0.06=$ & 0.0037 & $0.19=$ & 0.0117 & $0.14=$ & 0.0086 \\
\hline ISO 9000 & 0.0223 & $0.25=$ & 0.0055 & $0.25=$ & 0.0055 & $0.25=$ & 0.0055 & $0.25=$ & 0.0055 \\
\hline Package & 0.0080 & $0.24=$ & 0.0019 & $0.07=$ & 0.0005 & $0.55=$ & 0.0044 & $0.13=$ & 0.0010 \\
\hline $\begin{array}{l}\text { Manufacturing quality } \\
\text { Top management } \\
\text { committee }\end{array}$ & 0.0059 & $0.44=$ & 0.0025 & $0.07=$ & 0.0004 & $0.33=$ & 0.0019 & $0.14=$ & 0.0008 \\
\hline Customer focus & 0.0297 & $0.29=$ & 0.0086 & $0.06=$ & 0.0017 & $0.51=$ & 0.0151 & $0.12=$ & 0.0035 \\
\hline $\begin{array}{l}\text { Cost Direct cost Delivery } \\
\text { cost }\end{array}$ & 0.0265 & $0.12=$ & 0.0031 & $0.28=$ & 0.0074 & $0.52=$ & 0.0137 & $0.07=$ & 0.0018 \\
\hline Net price & 0.1457 & $0.15=$ & 0.0218 & $0.38=$ & 0.0553 & $0.38=$ & 0.0553 & $0.07=$ & 0.0101 \\
\hline Indirect cost Ordering cost & 0.0229 & $0.17=$ & 0.0038 & $0.47=$ & 0.0107 & $0.28=$ & 0.0064 & $0.07=$ & 0.0016 \\
\hline Capital investment & 0.0058 & $0.13=$ & 0.0007 & $0.48=$ & 0.0027 & $0.31=$ & 0.0017 & $0.06=$ & 0.0003 \\
\hline $\begin{array}{l}\text { Delivery Compliance with } \\
\text { due time Delivery lead time }\end{array}$ & 0.0214 & $0.07=$ & 0.0014 & $0.29=$ & 0.0062 & $0.50=$ & 0.0107 & $0.12=$ & 0.0025 \\
\hline Percentage late delivery & 0.0643 & $0.27=$ & 0.0173 & $0.12=$ & 0.0077 & $0.07=$ & 0.0045 & $0.53=$ & 0.0340 \\
\hline $\begin{array}{l}\text { Compliance with quantity } \\
\text { Location }\end{array}$ & 0.0123 & $0.11=$ & 0.0013 & $0.06=$ & 0.0007 & $0.27=$ & 0.0033 & $0.53=$ & 0.0065 \\
\hline $\begin{array}{l}\text { Management and } \\
\text { organization } \\
\text { Responsiveness } \\
\text { Quantity problem }\end{array}$ & 0.0031 & $0.14=$ & 0.0004 & $0.07=$ & 0.0002 & $0.53=$ & 0.0016 & $0.24=$ & 0.0007 \\
\hline Urgent delivery & 0.0123 & $0.56=$ & 0.0031 & $0.06=$ & 0.0007 & $0.14=$ & 0.0017 & $0.22=$ & 0.0027 \\
\hline Discipline Honesty & 0.0131 & $0.16=$ & 0.0020 & $0.15=$ & 0.0019 & $0.23=$ & 0.0030 & $0.07=$ & 0.0009 \\
\hline
\end{tabular}


Table 7 Continued.........

Procedural compliment
Environment

Environment

ISO 14000 certified

Waste management

Technical capability

Product range

Technical problem solving

Facility and capacity

Machinery

Infrastructure

Layout

Performance history

Product line

Product Variety

Financial Manufacturing

finical

Profit/sale trends

Finance stability

Capital and banking

history

Product financiallnterest

on payment

Discount

Turn-over

Total score

\begin{tabular}{|c|c|c|c|c|c|c|c|c|}
\hline 0.0024 & $0.49=$ & 0.0011 & $0.12=$ & 0.0002 & $0.30=$ & 0.0007 & $0.07=$ & 0.0001 \\
\hline 0.0046 & $0.25=$ & 0.0011 & $0.25=$ & 0.0011 & $0.25=$ & 0.0011 & $0.25=$ & 0.0011 \\
\hline 0.0013 & $0.55=$ & 0.0007 & $0.15=$ & 0.0001 & $0.07=$ & 0.0001 & $0.22=$ & 0.0002 \\
\hline 0.0028 & $0.11=$ & 0.0003 & $0.57=$ & 0.0015 & $0.24=$ & 0.0006 & $0.06=$ & 0.0001 \\
\hline 0.0011 & $0.38=$ & 0.0004 & $0.40=$ & 0.0004 & $0.09=$ & 0.0001 & $0.11=$ & 0.0001 \\
\hline 0.0011 & $0.30=$ & 0.0003 & $0.49=$ & 0.0005 & $0.14=$ & 0.0001 & $0.05=$ & 0.0001 \\
\hline 0.0016 & $0.49=$ & 0.0007 & $0.06=$ & 0.0001 & $0.13=$ & 0.0002 & $0.29=$ & 0.0004 \\
\hline 0.0004 & $0.51=$ & 0.0002 & $0.06=$ & 0.0001 & $0.15=$ & 0.0001 & $0.27=$ & 0.0001 \\
\hline 0.0005 & $0.23=$ & 0.0001 & $0.57=$ & 0.0002 & $0.14=$ & 0.0001 & $0.05=$ & 0.0001 \\
\hline 0.0018 & $0.28=$ & 0.0005 & $0.52=$ & 0.0009 & $0.13=$ & 0.0002 & $0.05=$ & 0.0001 \\
\hline 0.0040 & $0.05=$ & 0.0002 & $0.22=$ & 0.0008 & $0.58=$ & 0.0023 & $0.13=$ & 0.0005 \\
\hline 0.0169 & $0.05=$ & 0.0008 & $0.26=$ & 0.0043 & $0.13=$ & 0.0021 & $0.54=$ & 0.0091 \\
\hline 0.0064 & $0.31=$ & 0.0019 & $0.10=$ & 0.0006 & $0.06=$ & 0.0003 & $0.51=$ & 0.0032 \\
\hline 0.0005 & $0.05=$ & 0.0001 & $0.11=$ & 0.0001 & $0.28=$ & 0.0001 & $0.54=$ & 0.0002 \\
\hline 0.0025 & $0.28=$ & 0.0007 & $0.14=$ & 0.0003 & $0.28=$ & 0.0007 & $0.28=$ & 0.0007 \\
\hline \multirow[t]{2}{*}{0.0007} & $0.27=$ & 0.0001 & $0.14=$ & 0.0001 & $0.51=$ & 0.0003 & $0.06=$ & 0.0001 \\
\hline & & 0.1367 & & 0.2748 & & 0.1705 & 0.3947 & \\
\hline
\end{tabular}




\section{SENSITIVITY ANALYSIS OF RESULT}

Sensitivity analysis identifies the impact of changes in the priority of criteria for the suppliers' performance and order quantities. After obtaining the initial solution with the given weights of the attributes, sensitivity analyses were carried out to explore the response of the overall utility of alternatives and to changes in the relative importance (weight) of each attribute or criterion. The sensitivity analyses are necessary because changing the importance of attributes or criteria requires different levels of trust, quality, cost, delivery, management and organization, financial and sourcing opportunities for the alternatives. A series of sensitivity analyses were conducted using the Expert Choice $(E C)$ program.

Performance Sensitivity Analysis (PSA) of Expert Choice (EC), shown in (Fig. 2), represents the variation of suppliers' ranking to changes in each criterion. It illustrates the ratio of each alternative's weight percentage to criteria weights. The results show that in trust criteria supplier $C$ ranked in the highest grade and supplier $D$ ranked the lowest score. It can be seen that in delivery criteria supplier $D$ has the highest score and supplier $B$ has the lowest score. This dynamic performance analysis tool is configurable according to the important criteria's for purchasing managers in their projects. As an example, (Fig. 3) illustrates that if the "Management and organization" is important for the manager and it can be set to $70.6 \%$ and the "Trust" criteria are less important and the rate drop from $44.8 \%$ to $14.3 \%$, it can be concluded the ranking of suppliers is changed to supplier A followed by supplier C, B and D.

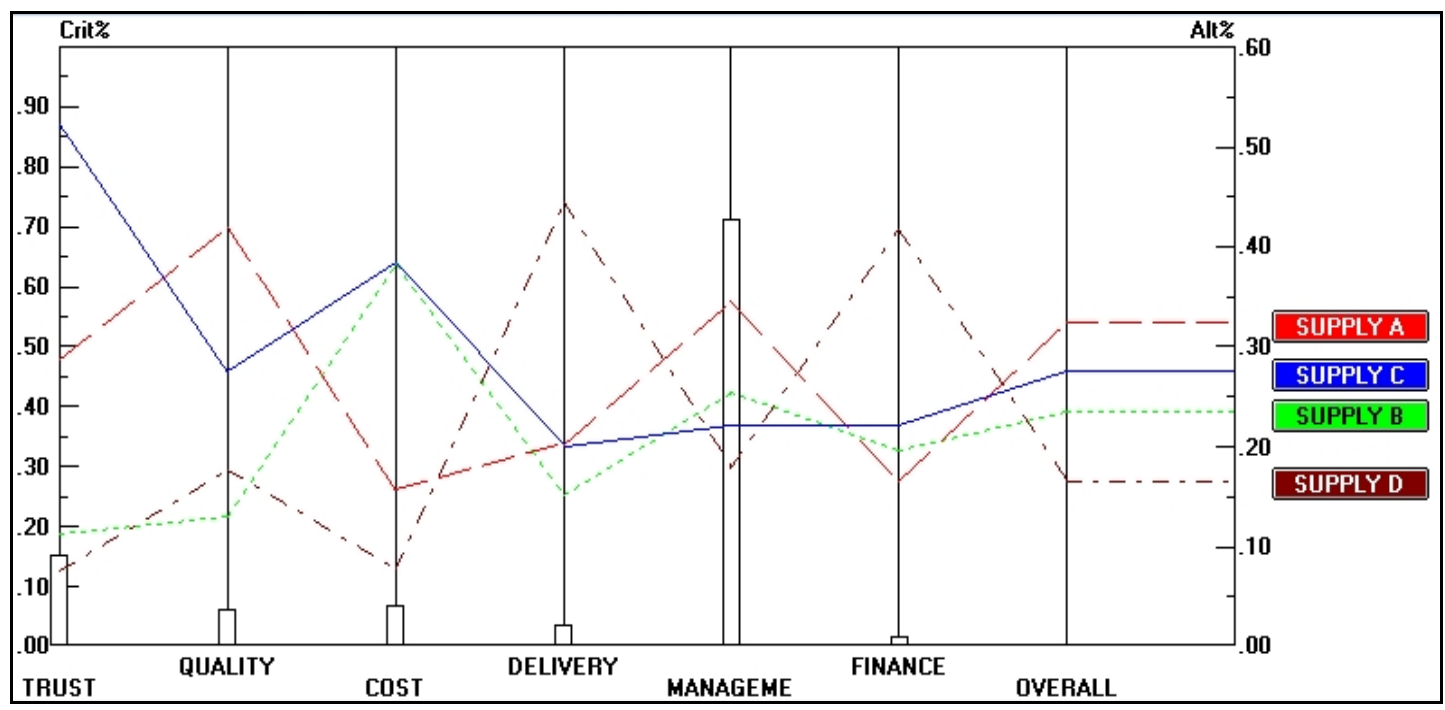

Fig. 3. Perform sensitivity analysis of supplier selection after change the score of management and organization and Trust criteria

Gradient Sensitivity Analysis (GSA) of Expert Choice (EC), which is shown in (Fig. 4), represents the variation of suppliers' ranking to changes in Management and organization criteria. It illustrates that if the Management and organization criterion, which is $70.6 \%$, increases to $85.9 \%$ or decreases to $51.7 \%$, the suppliers' ranking do not change. In the first area, if the weight of Management and organization is between $0 \%$ and $51.7 \%$ the ranking of suppliers will change in this order: supplier $C$ follows by supplier $A, B$ and $D$. The changes of the Management and organization criteria weighting in the third area are brought in Table 
8. It can be seen that within the three following areas of GSA the suppliers' ranking were not sensitive as shown in Table 8.

Table 8. Classifies suppliers' ranking within five areas

\begin{tabular}{lll}
\hline Area & Delivery criteria & Suppliers' ranking \\
\hline 1 & $0.00 \%-51.7 \%$ & $S_{C}>S_{A}>S_{B}>S_{D}$ \\
2 & $51.7 \%-85.9 \%$ & $S_{A}>S_{C}>S_{B}>S_{D}$ \\
3 & $85.9 \%-100 \%$ & $S_{A}>S_{B}>S_{C}>S_{D}$ \\
\hline
\end{tabular}

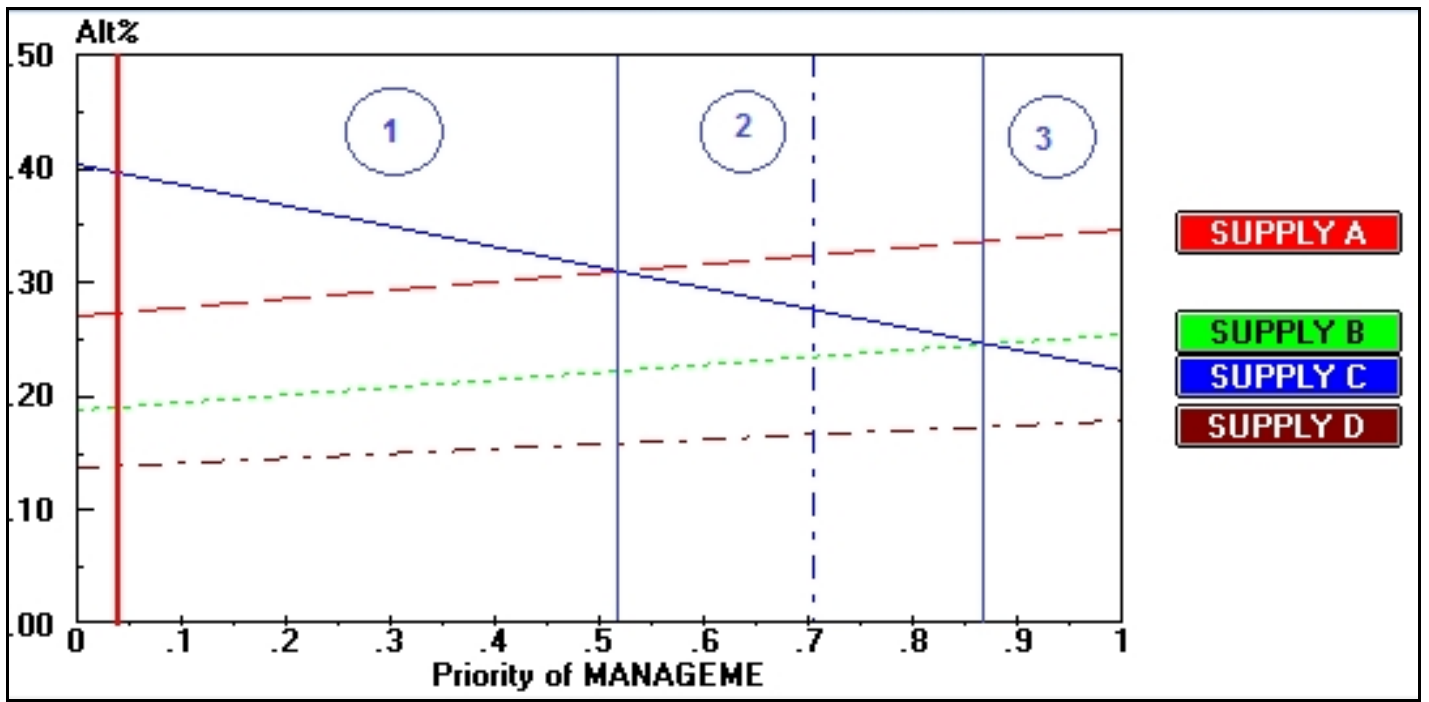

Fig. 4. Gradient sensitivity of supplier's performance on delivery

\section{CONCLUSION}

In this work, we developed a Fuzzy AHP multi-criteria decision making model for supplier evaluation and selection in the $A B C$ steel company as illustrated in Fig. 1. With the applicationof Fuzzy numbers, the Fuzzy AHP model has clear out-right advantages over other similar models. It effectively improves the flexibility of the convential AHP in dealing with the uncertainties and ambiguities associated with the judgements of different decision makers. The identification of the important criteria for supplier selection process is obtained based on our previous work [31]. The criteria found were Trust between key men, followed by net price and re-win percentage as can be seen in Table 6 . The four-level Fuzzy AHP model is assessing decision makers to easily identify, evaluate and select the suitable supplier. The foundation for the application of the proposed model was four suppliers and the results showed that the model precipitated correct decision making by examining the benefits and disadvantages of each given supplier through the use of the aforementioned criteria in the model. A series of sensitivity analyses were conducted using the Expert Choice (EC) program to evaluate and rank the suppliers based on the different priority weights of each criteria. Furthermore, the model is applicable to any supplier selection problem in the $A B C$ steel manufacturing company in Malaysia. In addition, the proposed Fuzzy AHP model is significantly effective in decision making. Moreover, this model can 
bereused to identify any supplier ranking case, in order to evaluate and compare other new future suppliers with consideration of both quantity and quality criteria in the $A B C$ steel manufacturing company.

\section{COMPETING INTERESTS}

Authors have declared that no competing interests exist.

\section{REFERENCES}

1. Ghodsypour SH, Brien CO. A decision support system for supplier selection using an integrated analytical hierarchy process and linear programming. International Journal of Production Economics. 1998;56(67):199-212.

2. Liu FHF, Hai HL. The voting analytic hierarchy process method for selecting supplier. International Journal of Production Economics. 2005;97(3):308-317.

3. Yahya S, Kingsman B. Vendor rating for an entrepreneur development programme: a case study using the analytic hierarchy process method. Journal of the Operational Research Society. 1999;50:916-930.

4. Chen-Tung C, Ching-Torng L, Huanget SF. A fuzzy approach for supplier evaluation and selection in supply chain management. Production Economics. 2006;102:289-301.

5. Rouyendegh BD, Erkan TE. Selection of academic staff using the fuzzy analytic hierarchy process (FAHP): A pilot study. Tehnicki vjesnik/Technical Gazette. 2012;19(4):923-929.

6. Dulmin R, Mininno V. Supplier selection using a multi-criteria decision aid method. Journal of Purchasing and Supply Management. 2003;9:177-187.

7. Rouyendegh BD, Erkan TE. Selecting the best supplier using analytic hierarchy process (AHP) method. Afr J Bus Manag. 2012;6(4):1455-1462.

8. Yusuff RD, PohYee K, Hashmi MSJ. A preliminary study on the potential use of the analytical hierarchical process (AHP) to predict advanced manufacturing technology (AMT) implementation. Robotics and Computer Integrated Manufacturing. 2001;17:421-427.

9. Tam MCY, Tummala VMR. An application of the AHP in vendor selection of a telecommunications system. Omega. 2001;29(2):171-182.

10. $\mathrm{Yu} X$, Jing $\mathrm{S}$. A decision model for supplier selection considering trust. Chinese Business Review. 2004;3(6):15-20.

11. Tahriri, Farzad, Osman, Mohd. Rasid, Aidy Ali. A review of supplier selection methods in manufacturing industries, Suranaree Journal of Science and Technology. 2008;15(3):201-208.

12. Ho W, Xu X, Dey PK. Multi-criteria decision making approaches for supplier evaluation and selection: A literature review. European Journal of Operational Research. 2010;202:16-24.

13. Aktepe, Adnan, Ersoz, Suleyman. A fuzzy analytic hierarchy process model for supplier selection and a case study. International Journal of Research and Development. 2011;3(1):33-37.

14. Wu DS, Olson DL. Supply chain risk, simulation and vendor selection. International Journal of Production Economics. 2008;114:646-655.

15. Kheljani JG, Ghodsypour SH, O'Brien C. Optimizing whole supply chain benefit versus buyer's benefit through supplier selection. International Journal of Production Economics. 2009;121:482-493. 
16. Lin CT, Chen CB, Ting YC. An ERP model for supplier selection in electronics industry. Expert Systems with Applications. 2011;38:1760-1765.

17. Bhattacharya, Geraghty J. Young PSupplier selection paradigm: An integrated hierarchical QFD methodology under multiple-criteria environment. Applied Soft Computing. 2010;10:1013-1027.

18. Moghadam MRS, Afsar A, Sohrabi B. Inventory lot-sizing with supplier selection using hybrid intelligent algorithm. Applied Soft Computing. 2008;8:1523-1529.

19. Wang JW, Cheng $\mathrm{CH}$, Kun-Cheng $\mathrm{H}$. Fuzzy hierarchical TOPSIS for supplier selection. Applied Soft Computing. 2009;9:377-386.

20. Omkarprasad SV, Kumar S. Analytic hierarchy process: An overview of applications. European Jurnal of Operational Research. 2006;169:1-29.

21. Vargas L. An overview of analytic hierarchy process: Its applications. European Journal of Operational Research. 1990;48(1):2-8.

22. Akarte MM. Web based casting supplier evaluation using analytic hierarchy process. Journal of the Operational Research Society. 2001;52(5):511-522.

23. Handfield R, Walton SV, Sroufe R. Applying environmental criteria to supplier assessment: A study in the application of the Analytical Hierarchy Process. European Journal of Operational Research. 2002;141:70-87.

24. Kwong CK, Bai H. A fuzzy AHP approach to the determination of importance weights of customer requirements in quality function deployment. Journal of Intelligent Manufacturing. 2002;13(5):367-377.

25. Laarhoven PJM, Pedrycz W. A fuzzy extension of Saaty's priority theory. Fuzzy Sets and Systems. 1983;11:229-241.

26. Zadeh LA. Fuzzy sets. Information and Control. 1965;8(4):338-353.

27. Tahriri, Farzad, Taha, Zahari. The concept of integrating Virtual Group (VG) and Agile Supplier Selection (ASS). Journal of Business Management and Economics. 2010;1(1):032-037.

28. Dickson GW. An analysis of vendor selection systems and decisions. Journal of Purchasing. 1966;2(1):5-17.

29. Weber CA, Current JR, Benton WC. Vendor selection criteria and methods. European Journal of Operational Research. 1991;50:2-18.

30. Zhang Z, Lei J, Cao N, To K, Ng K. Evolution of supplier selection criteria and methods. European Journal of Operational Research. 2003;4(1):335-342.

31. Tahriri, Farzad, Osman, Mohd. Rasid, Aidy Ali, Yusuff, Rosnah. Mohd, Esfandyari AR. AHP Approach for supplier evaluation and selection in steel manufacturing company. Journal of Industrial Engineering and Management. 2008;1(2):54-76.

32. Tullous R, Munson JM. Trade-offs under uncertainty: Implications for industrial purchasers. International Journal of Purchasing and Materials Management. 1991;27(3):24-31.

33. Bross ME, Zhao G. Supplier selection process in emerging markets - the case study of volvo bus corporation in China. Master Thesis. School of Economics and Commercial Law, Göteborg University; 2004.

34. Davidrajuh R. Automating supplier selection procedures. Doctor of engineering degree norwegian University of Science and Technology (NTNU). Narvik Institute of Technology Narvik, Norway; 2000.

35. Ku C, Chang $\mathrm{C}, \mathrm{Ho} \mathrm{H}$. Global supplier selection using fuzzy analytic hierarchy process and fuzzy goal programming. Quality and Quantity. 2010;44:623-640.

36. Kahraman U. Cebeci, Ulukan Z. Multi-criteria supplier selection using fuzzy AHP. Logistics Information Management. 2003;16:382-394. 
37. Awasthi A, Chauhan SS, Goyal SK. A fuzzy multi criteria approach for evaluating environmental performance of suppliers. International Journal of Production Economics. 2010;126:370-378.

38. Saaty T. The analytic hierarchy process. NY. McGraw-Hill; 1980.

39. Lious TS, Wang MJJ. Ranking fuzzy numbers with integral value. Fuzzy Sets System. 1992;50(3):247-255

(c) 2014 Tahriri et al.; This is an Open Access article distributed under the terms of the Creative Commons Attribution License (http://creativecommons.org/licenses/by/3.0), which permits unrestricted use, distribution, and reproduction in any medium, provided the original work is properly cited.

Peer-review history:

The peer review history for this paper can be accessed here:

http://www.sciencedomain.org/review-history. php?iid=482\&id=22\&aid=4238 